\title{
Mental health among outpatient reproductive health care providers during the US COVID-19 epidemic
}

\author{
Alison B. Comfort ${ }^{1 *}$ (1), Paul J. Krezanoski ${ }^{2}$, Lavanya Rao ${ }^{1}$, Alison El Ayadi ${ }^{1}$, Alexander C. Tsai ${ }^{4}$, Suzan Goodman ${ }^{3}$ \\ and Cynthia C. Harper ${ }^{1}$
}

\begin{abstract}
Introduction: Both inpatient and outpatient providers may be at increased risk of stress, anxiety and depression from their roles as health providers during the COVID-19 epidemic. This study explores how the US COVID-19 epidemic has increased feelings of stress, anxiety and depression among outpatient reproductive health providers.

Methods: We conducted a survey with open-ended responses among outpatient reproductive health providers across the U.S. engaged in contraceptive care to collect data on their experiences with stress, anxiety and depression during the COVID-19 epidemic. The study population included physicians, nurses, social workers, and other health professions [ $n=288]$. Data were collected from April 21st-June 24th 2020. We used content analysis of free text responses among providers reporting increased stress, anxiety or depression.
\end{abstract}

Results: Two-thirds (184) of providers reported increased stress and one-third (96) reported increased anxiety or depression related to care provision during the COVID-19 epidemic. The major sources of stress, anxiety and depression were due to patient care, worry about becoming infected or infecting family members, work- and home-related concerns, experiencing provider burnout, and fear of the unknown. Concerns about quality of patient care, providers'changing responsibilities, lack of personal protective equipment, and difficulty coping with co-worker illness and absence all contributed to provider stress and anxiety. Worries about unemployment and childcare responsibilities were also highlighted. Providers attributed their stress, anxiety or depression to feeling overwhelmed, being unable to focus, lacking sleep, and worrying about the unknown.

Conclusions: US outpatient providers are experiencing significant stress, anxiety, and depression during the US COVID-19 epidemic. Policy and programmatic responses are urgently needed to address the widespread adverse mental health consequences of this epidemic on outpatient providers, including reproductive health providers, across the US.

Plan English summary: Both inpatient and outpatient providers may be at increased risk of stress, anxiety and depression from their roles as health providers during the COVID-19 epidemic. This study explores how the US COVID-19 epidemic has increased feelings of stress, anxiety and depression among outpatient reproductive health providers across the US. We conducted a survey from April 21st to June 24th, 2020 among outpatient reproductive health providers, including physicians, nurses, social workers and other health professions. We asked open-ended

\footnotetext{
*Correspondence: Alison.comfort@ucsf.edu

${ }^{1}$ Bixby Center for Global Reproductive Health, Department of Obstetrics,

Gynecology, and Reproductive Sciences, University of California San

Francisco, 550 16th Street, 3rd floor, San Francisco, CA 94143, USA

Full list of author information is available at the end of the article
} original author(s) and the source, provide a link to the Creative Commons licence, and indicate if changes were made. The images or other third party material in this article are included in the article's Creative Commons licence, unless indicated otherwise in a credit line to the material. If material is not included in the article's Creative Commons licence and your intended use is not permitted by statutory regulation or exceeds the permitted use, you will need to obtain permission directly from the copyright holder. To view a copy of this licence, visit http://creativecommons.org/licenses/by/4.0/. The Creative Commons Public Domain Dedication waiver (http://creativeco mmons.org/publicdomain/zero/1.0/) applies to the data made available in this article, unless otherwise stated in a credit line to the data. 
questions to understand why providers reported increased stress, anxiety and/or depression. Two-thirds (184) of providers reported increased stress and one-third (96) reported increased anxiety or depression from care provision during the COVID-19 epidemic. Major sources of stress, anxiety and depression were due to patient care, worry about becoming infected or infecting family members, work- and home-related concerns, experiencing provider burnout, and fear of the unknown. Concerns about quality of patient care, providers' changing responsibilities, lack of personal protective equipment, and difficulty coping with co-worker illness and absence all contributed to provider stress and anxiety. Worries about unemployment and childcare responsibilities were also highlighted. Providers attributed their stress, anxiety or depression to feeling overwhelmed, being unable to focus, lacking sleep, and worrying about the unknown. This study highlights that US outpatient reproductive health providers are experiencing significant stress, anxiety, and depression during the US COVID-19 epidemic. Policy and programmatic responses are urgently needed to address the widespread adverse mental health consequences of this epidemic on outpatient providers, including reproductive health providers, across the US.

Keywords: COVID-19, Mental health, Stress, Anxiety, Outpatient providers, Reproductive health providers, Contraceptive care

\section{Introduction}

The severe coronavirus disease 2019 (COVID-19) pandemic has created significant challenges to the provision of health care in the US [1-3]. Front-line providers who treat COVID-19 patients in the emergency and inpatient settings face tremendously stressful working environments, with high patient mortality, inadequate supplies of personal protective equipment (PPE), and feelings of powerlessness and exhaustion due to patient volume. While the stress faced by front-line providers is apparent, the mental health consequences for providers, including reproductive health providers, offering care in the outpatient setting during this pandemic are less clear.

Access to comprehensive contraceptive services has become increasingly challenging during the COVID19 pandemic. Reproductive health providers have faced significant obstacles in offering comprehensive contraceptive services during this pandemic $[4,5]$. Contraceptive providers, similar to other health providers, have needed to adjust how care is provided to accommodate shelter-in-place and social distancing recommendations, respond to changes in clinic funding, and satisfy competing demands for their time for COVID-related care [5]. As a result of the changing nature of their roles in response to the pandemic, there are many ways in which these reproductive health providers may be at high risk of burnout, anxiety and depression. While there is an impending public health crisis from the mental health consequences of COVID-19 among the general population [6], there is also an urgent need to focus on the mental health implications among health care providers as well, including reproductive health providers.

There is growing interest in the implications of the epidemic on providers' stress levels, anxiety and depression [7-11]. Recent examples in the press have highlighted that providers are feeling overwhelmed [12]:
"In a medical crisis, my job is to manage a clinical team, problem-solve and be in control. It is hard to admit that I feel vulnerable and scared... But I am admitting it because you need to know how close health care workers are to breaking." Emergency Medicine Physician, Arizona

Emblematic of these challenges are at least two wellpublicized examples of health care providers in the US who have died by suicide during this pandemic [13-15]. While these deaths cannot be directly attributed to providing care during this pandemic, the timing and circumstance of these tragedies requires that we look further into the mental health pressures of the COVID-19 pandemic.

Due to the nature of their work even before COVID-19, health providers face increased risks of stress, burnout, anxiety and depression [16-21]. These adverse consequences have been linked to decreased effectiveness, poor quality of care, and adverse personal consequences such as substance abuse, depression, and suicide [16, 22-25]. There has been limited data, however, measuring the mental health impact of the COVID-19 pandemic on health providers. A recent study on obstetricians and gynecologists in the US highlighted the compassion fatigue and shared trauma experienced by providers as a result of their proximity to the suffering of patients during the COVID-19 pandemic [26]. In China, a high proportion of providers treating patients with COVID-19 reported symptoms of depression, anxiety, insomnia, and distress [11]. Similar patterns were documented in Italy and Canada [27, 28]. A study in the US during the first few weeks of the pandemic identified multiple sources of anxiety [29], and a recent survey among US emergency physicians found increased levels of stress, burnout and emotional exhaustion during the epidemic compared to pre-pandemic levels [30]. 
There is no known research on the mental health consequences of the COVID-19 epidemic among reproductive health providers in the US. In this study, we investigated reproductive health providers with a focus on understanding how changes in provider roles have impacted feelings of stress, anxiety and depression. We used open-ended questions to capture, in their own voices, providers' experiences with care provision during this epidemic to expand our knowledge of the impacts of COVID-19 on health care in the US.

\section{Materials and methods}

\section{Study sample and data collection}

We conducted our study among a convenience sample of reproductive health providers engaged in contraceptive care across different practice settings throughout the US. The study sample was recruited from reproductive health providers who had participated in a Continuing Medical Education-accredited contraceptive training course conducted by the University of California San Francisco School of Medicine, Department of Obstetrics and Gynecology in the past five years. Participants included those who offer clinical care or counseling about contraception. These providers worked across different outpatient settings, though some also provided inpatient care.

An online survey was emailed through Qualtrics to study participants between April 21st to June 24th 2020 that included open-ended response items on experiences during the COVID-19 epidemic. A total of 2901 surveys were emailed to potential study participants, with 3-5 reminder emails. 288 providers consented to participate in the study and met the eligibility criteria of providing clinical care, counseling, or education about contraception (10\% response rate). The response rate is a significant under-estimate because certain providers were no longer working and retired when contacted. We presented descriptive statistics of the sample $(n=288)$. Then we focused our analysis on the free text responses of the providers who reported experiencing stress, anxiety or depression due to their work during COVID-19 epidemic, among the larger study sample of surveyed providers reporting on how care provision has changed. This analytical sample consisted of the 187 providers of the 288 who reported experiencing stress, anxiety and/ or depression. Providers were asked, "In what ways have you as a provider been affected by the COVID-19 pandemic?" with "Stress" and "Anxiety/Depression" included in response categories. If participants checked either category, they were asked an open-ended follow-up question about how COVID-19 pandemic had increased these feelings. Participants who completed the survey were entered into a drawing to win a $\$ 250$ amazon giftcard. The study was approved by the UCSF Institutional Review Board.

\section{Statistical analysis}

Data were presented from the full sample of reproductive health providers completing the survey to compare socio-demographic characteristics and calculate the prevalence of providers experiencing stress, anxiety and/ or depression. We then conducted a content analysis of the free text responses among the analytical sample of those providers reporting having experienced stress, anxiety and/or depression. After inductive code generation from the open-ended responses by the first author, survey responses were coded separately by the third author. The first and third author then met to resolve any inconsistencies with coding and synthesize their assessments. Key themes arising from the data were identified and summarized the findings across the themes. Representative quotes were selected to highlight examples within each theme. The analysis focused both on the frequency of different concepts and the salience of particular responses to the overall topic of the mental health impacts of the COVID-19 epidemic. Qualitative data were analyzed in Atlas.ti.

\section{Results}

\section{Descriptive statistics of sample}

Among the study participants $(\mathrm{n}=288), 187$ participants (65\%) reported feelings of stress, anxiety and/or depression. This sample of providers who reported increased stress, anxiety and/or depression $(\mathrm{n}=187)$ included 32 (18\%) physicians, 8 (4\%) physician's assistants, $53(29 \%)$ nurse practitioners and certified nurse midwives, 34 $(19 \%)$ registered nurses, 6 (3\%) other nurses, 7 (4\%) medical assistants, 6 (3\%) health educators/social workers, 20 (11\%) managers/directors, 15 administrative staff (8\%), and 1 nursing/medical student (1\%) (Table 1). On average, providers were 46 years old and 168 (92\%) identified as female. Among this sample, 113 identified as White (62\%), 14 (8\%) as Black, 30 (16\%) as Hispanic/Latinx, 19 (10\%) as Asian/Pacific Islander, 4 (2\%) as Native American, and $2(1 \%)$ as other race/ethnicity. Practice settings varied with 83 (45\%) from primary care and health departments, 58 (32\%) from family planning and abortion clinics, $9(5 \%)$ from outpatient clinics at hospitals, 35 (19\%) from youth/student health center, and 23 (12\%) from other practice settings. Providers spanned 25 states covering all regions: Northeast (21 [11\%]), Midwest (17 [9\%]), Southeast (49 [26\%]), Southwest (388 [26\%]), and West (52 [28\%]). Chi-squared testing was conducted to assess any differences in characteristics between provider who had versus those who had not experienced increased stress, anxiety and/or depression. There were 
Table 1 Summary characteristics of providers

\begin{tabular}{|c|c|c|c|c|c|}
\hline & \multicolumn{2}{|c|}{$\begin{array}{l}\text { Full Sample } \\
(n=288)\end{array}$} & \multicolumn{2}{|c|}{$\begin{array}{l}\text { Sample of providers } \\
\text { affected by feelings } \\
\text { of stress, anxiety } \\
\text { or depression } \\
(\mathrm{n}=187)\end{array}$} & \multirow[t]{2}{*}{$\begin{array}{l}\mathrm{X}^{2} \text { comparison of sample that did versus did } \\
\text { not report increased stress/anxiety/depression }\end{array}$} \\
\hline & $\mathbf{n}$ & $\%$ & $\mathrm{n}$ & $\%$ & \\
\hline \multicolumn{6}{|l|}{ Sex, n (\%) } \\
\hline Female & 251 & 94 & 168 & 92 & $x^{2}=3.10$ \\
\hline Male & 14 & 5 & 12 & 7 & $p=0.21$ \\
\hline Other/non-binary & 2 & 1 & 2 & 1 & \\
\hline Age (mean $\pm S D)$ & $46.4 \pm 11.5$ & & $46.0 \pm 11.4$ & & t-stat $=0.92, p=0.36$ \\
\hline \multicolumn{6}{|l|}{ Race/ethnicity, n (\%) } \\
\hline White & 165 & 62 & 113 & 62 & $x^{2}=8.38$ \\
\hline Black & 29 & 11 & 14 & 8 & $p=0.14$ \\
\hline Hispanic/Latinx & 40 & 15 & 30 & 16 & \\
\hline Asian/Pacific Islander & 26 & 10 & 19 & 10 & \\
\hline Native American & 4 & 2 & 4 & 2 & \\
\hline Other & 3 & 1 & 2 & 1 & \\
\hline \multicolumn{6}{|l|}{ Provider type, $n(\%)$} \\
\hline Physician & 44 & 16 & 32 & 18 & $x^{2}=16.39$ \\
\hline Physician's Assistant & 14 & 5 & 8 & 4 & $p=0.06$ \\
\hline Nurse Practitioner/ Certified Nurse Midwife & 82 & 30 & 53 & 29 & \\
\hline Registered Nurse & 61 & 23 & 34 & 19 & \\
\hline Other Nurse & 7 & 3 & 6 & 3 & \\
\hline Medical Assistant & 11 & 4 & 7 & 4 & \\
\hline Health Educator/Social worker & 7 & 3 & 6 & 3 & \\
\hline Manager/Director & 24 & 9 & 20 & 11 & \\
\hline Administrative staff & 17 & 6 & 15 & 8 & \\
\hline Student & 3 & 1 & 1 & 1 & \\
\hline \multicolumn{6}{|l|}{ Education, $\mathrm{n}(\%)$} \\
\hline High school, GED, technical or vocational & 13 & 5 & 9 & 5 & $x^{2}=0.40$ \\
\hline Two-year college degree & 21 & 8 & 13 & 7 & $p=0.98$ \\
\hline Four-year college degree & 61 & 23 & 43 & 24 & \\
\hline Graduate or professional & 163 & 61 & 111 & 61 & \\
\hline Other & 8 & 3 & 6 & 3 & \\
\hline \multicolumn{6}{|l|}{ Practice setting, n (\%) } \\
\hline Primary care/Heath department & 123 & 43 & 83 & 45 & $x^{2}=1.52$ \\
\hline Family planning/abortion clinics & 97 & 34 & 58 & 32 & $p=0.68$ \\
\hline Youth/student clinics & 52 & 18 & 35 & 19 & \\
\hline Hospital/Other & 16 & 6 & 9 & 5 & \\
\hline \multicolumn{6}{|l|}{ Region, $n(\%)$} \\
\hline Northeast & 35 & 12 & 21 & 11 & $x^{2}=5.2723$ \\
\hline Midwest & 26 & 9 & 17 & 9 & $p=0.260$ \\
\hline Southeast & 90 & 31 & 49 & 26 & \\
\hline Southwest & 76 & 26 & 38 & 26 & \\
\hline West & 69 & 23 & 52 & 28 & \\
\hline
\end{tabular}

The last column represents chi-square (for categorical) and t-tests (for continuous) comparisons between the sample that reported increased stress, anxiety and depression and the sample that did not 
no statistically significant differences by age, gender, race/ ethnicity, provider type, practice setting, or geographic region (Table 1).

Most reproductive health providers reported that their clinic was currently open and providing telehealth services (109 [58\%]) (Table 2). At the time of the survey, three-fourths of providers (135 [75\%]) said their county was re-opening with restrictions, while one-fifth said they were still under stay-at-home/shelter-in-place orders $(40[22 \%])$.

Among the sample of providers, two-thirds (184 [66\%]) said they felt increased stress when asked in what ways they have been affected by COVID-19 (Table 2). In addition, one-third (96 [35\%]) reported the epidemic had increased feelings of anxiety/depression. Other ways that providers reported they were affected by the COVID-19 epidemic included: fear of going to clinic/getting sick (110 [40\%]), shift towards COVID-19 related care (113 [41\%]), shift away from their primary roles (72 [26\%]), and absenteeism (due to own illness, family illness or care-giving) (43 [16\%]).

Responses to the open-ended questions about increased feelings of stress and/or anxiety/depression centered on the following key themes: patient care, worry about own or family infection, financial and employment-related concerns, childcare, provider distress/ burnout, and the fear of the unknown. Within each of these themes, several sub-themes emerged.

\section{Patient care}

The most commonly reported reasons for increased stress, anxiety and depression were feelings of inadequacy around patient care and follow-up. Providers were concerned that patients would not know how to access care, that patients may be isolated during shelter-inplace, and might have no way to seek help. Reproductive health providers mentioned challenges in finding new ways to offer the same quality of care, limitations of telehealth visits, and concerns that patients were not able to access care:

"I hate for a client to not know [if] they can still come see or call us. We are here for them still." Clinic Manager, Family Planning Clinic, Tennessee

Study participants were also concerned that nonCOVID-19 patients were not getting the needed care during this time, due to attention focused on addressing COVID-19:

"Concern for so much focus on COVID-19 leading to worsening of other health conditions."

Physician Assistant, County Health Department, North Carolina

Table 2 Ways that providers have been affected by COVID-19 pandemic and clinic status

\begin{tabular}{|c|c|c|}
\hline & $\mathbf{n}$ & $\%$ \\
\hline \multicolumn{3}{|l|}{ Sample $=$ all providers $(n=288)$} \\
\hline \multicolumn{3}{|l|}{ In what ways have you as a provider been affected by COVID-19? } \\
\hline Stress & 184 & 66 \\
\hline Anxiety or depression & 96 & 35 \\
\hline Fear of going to clinic or getting sick & 110 & 40 \\
\hline Shift towards providing COVID-19 related care & 113 & 41 \\
\hline Shift towards administrative work (adjusting protocols, time in meetings) & 114 & 41 \\
\hline Shift away from sexual and reproductive health services & 72 & 26 \\
\hline Absenteeism (due to own illness, family illness, school closures) & 43 & 16 \\
\hline Decreased staff hours & 72 & 26 \\
\hline Increased staff hours & 36 & 13 \\
\hline \multicolumn{3}{|l|}{ Sample $=$ providers who were affected by stress, anxiety or depression $(n=187)$} \\
\hline \multicolumn{3}{|l|}{ Current status of clinic (at time of survey) } \\
\hline Closed completely & 3 & 2 \\
\hline Closed on-site but providing services through telehealth & 35 & 19 \\
\hline Open on-site and providing services through telehealth & 109 & 58 \\
\hline Open on-site but not providing services through telehealth & 40 & 21 \\
\hline \multicolumn{3}{|l|}{ Current status of stay-at-home orders (at time of survey) } \\
\hline Stay-at-home/ shelter-in-place order & 40 & 22 \\
\hline Re-opening with restrictions & 135 & 75 \\
\hline Completely open & 5 & 3 \\
\hline
\end{tabular}




\section{Sudden increase in responsibilities due to COVID-19 related care}

Thirty percent of the whole sample $(n=288)$ had shifted service provision towards COVID-19 related care. Among the providers experienced increased stress, anxiety and/or depression $(n=187)$, they reported having more administrative tasks, increased hours, extra responsibilities, and being short-staffed, including due to staff illness and quarantines. A clinic manager explained that their stress was due to:

"Increased workload, little sleep, urgent changes, and ever-changing needs."

Clinic Manager, Family Planning Clinic, Virginia

In addition, several providers were now responsible for new roles, such as epidemic response planning or COVID-19 testing tent management. One nurse described increased responsibilities:

"Majority of our staff are assisting at the COVID drive-thru testing centers but weekly we are testing approximately 300 people in a four-hour span. It is hot, we are worn out. Then [we] are calling all of the positive and also doing the contract tracing and mailing every person that gets tested a copy of their result, positive or negative...We no longer have volunteers assisting us...[W]e are managing our normal daily routines of answering the phone calls, rescheduling patients that were scheduled prior to COVID that have to be changed to telemedicine visits."

\section{Registered Nurse, Family Planning Clinic, Louisiana}

In instances where clinics remained open while other nearby or related clinics were closed, providers mentioned that the resulting increased patient caseload was also a source of stress.

\section{Changing clinical guidelines and protocols}

The need for providers to quickly and continuously adapt to changing clinical guidelines and protocols was another source of stress and anxiety. This included confusion about recommendations and the consequent stress of clinical decision-making. A nurse practitioner said:

"More worry and concern; the unknown. Changes daily. This is going to be the new 'normal'. Not looking forward to how medicine will be done in future." Nurse Practitioner, Youth/Student Health Center, Oregon

A physician in leadership explained:

"I work in leadership, and I need to lead very unpopular changes that I myself don't agree with."
Internal Medicine Physician, Primary Care Clinic, Minnesota

\section{Telehealth visits}

Navigating telehealth was a significant source of stress. Seventy-seven percent of reproductive health providers said they were currently offering telehealth services during the epidemic, with most of them offering a mix of inperson and telehealth visits. Providers expressed feeling stressed due to the challenges of integrating telehealth visits, not being able to provide full patient exams, and feeling that they had limited resources to care for both COVID-19 and non-COVID-19 patients over the phone/ video. One provider attributed their stress and anxiety to:

"Fear of missing diagnoses due to telehealth or attention distracted by COVID-19."

Physician Assistant, Primary Care Clinic, North

Carolina

\section{Anxiety about COVID-19 among patients and staff}

Another stressor was related to managing both patients' and other staff's stress and anxiety about COVID-19. Providers gave examples of "watching patients struggle." One provider even gave an example of patients becoming more aggressive. Providers also mentioned their own feelings of stress and anxiety related to potentially contracting COVID-19, as well as illness and death among co-workers and patients. In addition to these fears, providers' need to remain professional while experiencing these situations took a significant toll:

"Responsibility to present a calm and supportive environment to patients and staff causes a repression of your own stress. This is exhausting... I have depleted my emotional reserves calming others."

Clinic Manager, Primary Care Clinic, New Mexico

\section{Worry about COVID-19 infection and/or infecting family}

Providers not surprisingly experienced stress and anxiety related to worries about becoming infected and/or infecting their family. One provider referred to feeling vulnerable because of underlying medical conditions. Other providers described their concerns as follows:

\section{"Always wondering if this is the day that I get the virus." \\ Counselor/Health Educator, Family Planning Clinic, Pennsylvania}

One provider said that, as a result of concern of infecting their family, they were now living apart from their family. Several providers highlighted the lack of PPE as 
a stressor. Providers also expressed concern about exposure due to asymptomatic patients.

\section{Financial and employment concerns}

Another source of stress and anxiety was due to financial concerns, including job stability, decreased hours and income, as well as potential and actual layoffs for themselves, partners, or other family members. One nurse midwife explained:

"I feel that our administration does not care about patients or quality of care, and that my hard work is not valued in the least. I might be fired like many colleagues at any moment, by text or phone, and I have dedicated my career to serving others through health care, particularly to those marginalized." Certified Nurse Midwife, Primary Care Clinic, New Mexico

\section{Home-related concerns including childcare}

Another source of stress related to concerns about childcare and the challenges of managing home schooling of children. One provider gave the example of not being able to find childcare, while another described relying on family to provide childcare with accompanying worry about family becoming ill. Another provider said their stress was due to being on duty on all fronts:

"Home all the time working full time and homeschooling 3 children."

Family Practice Physician, Primary Care Clinic, California

\section{Provider distress and burnout}

There were several examples of provider distress, overwhelm, overwork, and burnout. One provider simply said: One provider explained how their work has increased their feelings of stress by simply saying:

"I can't explain it- it's horrible."

Registered Nurse, Family Planning Clinic, Tennessee

Providers mentioned not being able to focus and facing decreased motivation to work.

"Feeling overwhelmed, stressed, unsure of what is right or wrong. Don't want to come to work. Feeling down and don't feel like I have support."

Nurse Practitioner, School-based Health Center, Oregon

Several providers mentioned lack of sleep, either due to work or to worrying, as contributing to anxiety:

"I wake up in the middle of the night worrying about
COVID."

Registered Nurse, Family Planning Clinic, Louisiana

Several providers mentioned increasing burnout. Providers also referenced isolation as one of the causes of stress and anxiety. A few even related the isolation to their altered working conditions:

"Stuck alone in an office all day with little to no patient interaction."

Registered Nurse, Family Planning Clinic, Georgia

\section{Fear of the unknown}

Finally, another common theme that increased feelings of stress and anxiety related to the fear of the unknown. The unknown was mentioned in relation to COVID19 , uncertainty about when services would re-open, the future of their clinic or organization, and about the virus.

"The unknown always causes anxiety. When will our operations go back to normal? Will there be another spike and will we have to close again?" Clinic Manager/Director, Family Planning Clinic, Montana

\section{Discussion}

This qualitative study offers timely evidence of how providing care during the US COVID-19 epidemic exacerbates provider stress, anxiety, and depression among US reproductive health providers. There is limited evidence focusing on the mental health consequences for outpatient providers, including reproductive health providers, across different practice settings. This study presents national data across different practice settings and provider types showing that even reproductive health providers, not commonly considered to be on the "front lines" of COVID-19 care, are experiencing negative mental health repercussions. There were no differences by age, gender, race/ethnicity, provider type, practice setting or geographic region between those who reported experiencing stress, anxiety or depression and those who did not, indicating that providers of all types are all facing stress and anxiety as a result of the epidemic. Many providers reporting stress, anxiety or depression mentioned changes in job responsibilities, with several examples of providers managing testing sites. Patient care concerns were one of the main sources of provider distress, with worries about the quality of care, follow-up, COVID19 management, and access to care for non-COVID-19 patients. The constant need to adapt to changing clinical guidelines and telehealth were also frequently mentioned. Providers noted the challenges of coping with co-worker illness, absence, and deaths. Other sources of stress, 
anxiety and depression centered around inadequate PPE, fear of coming to work and fear of getting sick or getting family members sick. Financial concerns, including apprehension about unemployment, contributed to provider distress. Childcare responsibilities also represented a challenge. Providers also attributed stress, anxiety and depression to feeling to feeling overwhelmed, being unable to focus, getting insufficient sleep. Finally, the fear of the unknown, related to the disease, the clinic, and implications for their communities and the country as a whole, was mentioned as a source of stress and anxiety.

Our study's findings, in addition to other recent studies $[11,27,29,30]$, point to the urgent need to ensure that providers across the entire health system have the resources and support to cope with the mental health consequences of providing health care during this epidemic. Several perspective articles have raised concerns about the mental health repercussions of COVID-19 on providers [7-10, 31, 32]. Interventions designed for the new realities of care provision during this epidemic should focus on reducing stigma as a barrier to health providers accessing treatment for mental illness [33-35]; identifying early warning signs of anxiety and depression; providing counseling, treatment and psychosocial support [8,32, 36]; reducing burnout through structural changes to reduce administrative burdens and residency work hour requirements [18, 37]; and increasing pay and job security for health workers at the bottom of the income distribution [38].

The study has limitations. The sample represents a convenience sample of reproductive health providers in outpatient settings and is not generalizable to all providers in the US. Future research would benefit from a nationally representative sample of outpatient reproductive health providers to provide generalizable results for the US. The study relied on open-ended text responses from a survey and did not use an in-depth interview guide which could provide nuanced responses. However, the open-ended text responses allowed for a larger sample size. The survey did not diagnose clinical anxiety or depression among study participants. Due to the survey design, only providers that mentioned having experienced stress, anxiety and/or depression during the pandemic responded to the follow-up open-ended question to describe how stress, anxiety and/or depression had increased. Some providers may have experienced less stress, anxiety and/or depression due to changes during the pandemic, but these are not captured in the response categories.

\section{Conclusions}

The COVID-19 pandemic is resulting in many lives lost, including among health providers [39]. In addition, reproductive health providers are experiencing significant stress, anxiety, and depression as a result of providing care during the US COVID-19 epidemic. These consequences not only have deleterious effects on the personal health of these providers but may also affect the quality of care that they are able to offer at the exact moment when high quality care is most crucial. Policy and programmatic responses are critically needed to address the adverse mental health consequences of providing care during this pandemic, including among reproductive health providers.

\section{Abbreviations \\ COVID-19: Severe coronavirus disease 2019; PPE: Personal protective equipment.}

\section{Acknowledgements}

We would like to thank the providers from across the country who participated in this survey to provide valuable information on their experience with care provision during the US COVID-19 epidemic.

\section{Authors' contributions}

AC conceptualized the study, analyzed the qualitative data, and drafted the manuscript. PK assisted in interpreting the data and revising the manuscript. LR analyzed the qualitative data and revised the manuscript. AA assisted in interpreting the data and revising the manuscript. AT made contributions to analyses and revised the manuscript. CH made contributions to manuscript conception and design of work. All authors read and approved the final manuscript.

\section{Funding}

This study was funded by the JPB Foundation (Grant Number 1088). The funding body had no role in the design of the study, the collection, analysis, and interpretation of data, and in writing the manuscript.

\section{Availability of data and materials}

The datasets used and/or analysed during the current study are available from the corresponding author on reasonable request.

\section{Ethics approval and consent to participate}

The study was approved by the UCSF Institutional Review Board.

\section{Consent for publication}

Not applicable.

\section{Competing interests}

The authors declare that they have no competing interests.

\section{Author details}

${ }_{1}^{1}$ Bixby Center for Global Reproductive Health, Department of Obstetrics, Gynecology, and Reproductive Sciences, University of California San Francisco, 550 16th Street, 3rd floor, San Francisco, CA 94143, USA. ${ }^{2}$ Department of Medicine, University of California San Francisco, Zuckerberg San Francisco General Hospital, 1001 Potrero Ave, San Francisco, CA 94110, USA. ${ }^{3}$ Bixby Center for Global Reproductive Health, Department of Family and Community Medicine, University of California San Francisco, 550 16th Street, 3rd floor, San Francisco, CA 94143, USA. ${ }^{4}$ Massachusetts General Hospital, Harvard Medical School, 125 Nashua Street, Suite 722, Boston, MA 02114, USA.

Received: 7 October 2020 Accepted: 9 February 2021

Published online: 24 February 2021

\section{References}

1. Kishore S, Hayden M. Community Health Centers and Covid-19 — Time for Congress to Act. N Engl J Med. 2020;383(8):e54. 
2. Grimm C. Hospital Experiences Responding to the COVID-19 Pandemic: Results of a National Pulse Survey March 23-27, 2020. Washington, D.C.; 2020.

3. Khullar D, Bond AM, Schpero WL. COVID-19 and the Financial Health of US Hospitals. JAMA. 2020;323(21):2127-8.

4. Nanda K, Lebetkin E, Steiner MJ, Yacobson I, Dorflinger LJ. Contraception in the Era of COVID-19. Global Health: Science and Practice. 2020:GHSP-D-20-00119.

5. Townsend JW, Ten Hoope-Bender P, Sheffield J. In the response to COVID19 , we can't forget health system commitments to contraception and family planning. International Journal of Gynaecol Obstetr. 2020.

6. Auerbach J, Miller BF. COVID-19 exposes the cracks in our already fragile mental health system. Am J Public Health. 2020;110(7):969-70.

7. Hartzband P, Groopman J. Physician Burnout, Interrupted. N Engl J Med. 2020;382(26):2485-7.

8. American Medical Association. Caring for our caregivers during COVID19. 2020. https://www.ama-assn.org/delivering-care/public-health/carin g-our-caregivers-during-covid-19 Accessed 4 Aug 2020.

9. Sasangohar F, Jones SL, Masud FN, Vahidy FS, Kash BA. Provider Burnout and fatigue during the COVID-19 pandemic: lessons learned from a highvolume intensive care unit. Anesth Analg. 2020;131(1):106-11.

10. Ayanian J. Mental Health Needs of Health Care Workers Providing Frontline COVID-19 Care. JAMA Health Forum. 2020.

11. Lai J, Ma S, Wang Y, Cai Z, Hu J, Wei N, et al. Factors associated with mental health outcomes among health care workers exposed to coronavirus disease 2019. JAMA Network Open. 2020;3(3):e203976.

12. Dreifuss B. I'm a Health Care Worker. You Need to Know How Close We Are to Breaking. The New York Times. 2020;Sect. Opinion. https:// www.nytimes.com/2020/06/26/opinion/coronavirus-arizona-hospitals. html?action $=$ click\&module=Opinion\&pgtype=Homepage Accessed 4 Aug 2020.

13. Watkins A, Rothfelt M, Rashbaum W, Rosenthal B. Top E.R. Doctor Who Treated Virus Patients Dies by Suicide. The New York Times. 2020. https ://www.nytimes.com/2020/04/27/nyregion/new-york-city-doctor-suici de-coronavirus.html Accessed 4 Aug 2020.

14. Knoll C, Watkins A, M R. 'I Couldn't Do Anything': The Virus and an E.R. Doctor's Suicide. The New York Times. 2020 July 11, 2020. https://www. nytimes.com/2020/07/11/nyregion/lorna-breen-suicide-coronavirus.html Accessed 4 Aug 2020

15. Tracy T. Off -duty FDNY EMT who just started career in January takes his own life: officials. New York Daily News. 2020. https://www.nydailynew s.com/new-york/nyc-crime/ny-off-duty-fdny-emt-dies-suicide-20200 425-6amplz5ptzel5i36pa75la2wam-story.html Accessed 4 Aug 2020.

16. Shanafelt TD, Sloan JA, Habermann TM. The well-being of physicians. Am J Med. 2003;114(6):513-9.

17. Shanafelt TD, Boone S, Tan L, Dyrbye LN, Sotile W, Satele D, et al. Burnout and satisfaction with work-life balance among US physicians relative to the general US Population. Arch Intern Med. 2012;172(18):1377-85.

18. Rotenstein LS, Torre M, Ramos MA, Rosales RC, Guille C, Sen S, et al. Prevalence of burnout among physicians: a systematic review. JAMA. 2018:320(11):1131-50.

19. Cohen JS, Patten S. Well-being in residency training: a survey examining resident physician satisfaction both within and outside of residency training and mental health in Alberta. BMC Med Educ. 2005;5:21.

20. Hsu K, Marshall V. Prevalence of depression and distress in a large sample of Canadian residents, interns, and fellows. Am J Psychiatry. 1987;144(12):1561-6.

21. Tyssen R, Hem E, Gude T, Grønvold NT, Ekeberg O, Vaglum P. Lower life satisfaction in physicians compared with a general population sample: a 10-year longitudinal, nationwide study of course and predictors. Soc Psychiatry Psychiatr Epidemiol. 2009;44(1):47-54.

22. Stehman CR, Testo Z, Gershaw RS, Kellogg AR. Burnout, Drop Out, suicide: physician loss in emergency medicine, Part I. Western J Emerg Med. 2019;20(3):485-94.
23. Zivin K, Brower KJ, Sen S, Fowler R, Gold KJ. Relationship between faculty characteristics and emotional exhaustion in a large academic medical center. J Occup Environ Med. 9000; Publish Ahead of Print.

24. Wallace JE, Lemaire JB, Ghali WA. Physician wellness: a missing quality indicator. The Lancet. 2009;374(9702):1714-21.

25. Airagnes G, Lemogne C, Olekhnovitch R, Roquelaure Y, Hoertel N, Goldberg $\mathrm{M}$, et al. Work-related stressors and increased risk of benzodiazepine long-term use: findings from the CONSTANCES Population-Based Cohort. Am J Public Health. 2018;109(1):119-25.

26. Werner EA, Aloisio CE, Butler AD, D’Antonio KM, Kenny JM, Mitchell A, et al. Addressing mental health in patients and providers during the COVID-19 pandemic. Semin Perinatol. 2020;1:151279.

27. Rossi R, Socci V, Pacitti F, Di Lorenzo G, Di Marco A, Siracusano A, et al. Mental health outcomes among front and second line health workers associated with the COVID-19 pandemic in Italy. medRxiv. 2020:2020.04.16.20067801.

28. Potluc. Potloc Study: Canadian health workers share their insights from the front lines of the COVID-19 pandemic. 2020. https://potloc.com/ blog/en/potloc-study-canadian-health-workers-insights-front-lines-covid -19-pandemic/

29. Shanafelt T, Ripp J, Trockel M. Understanding and addressing sources of anxiety among health care professionals during the COVID-19 Pandemic. JAMA. 2020;323(21):2133-4.

30. Rodriguez, R.M., Medak, A.J., Baumann, B.M., Lim, S., Chinnock, B., Frazier, R., Cooper, R.J. Academic Emergency Medicine Physicians' Anxiety Levels, Stressors, and Potential Stress Mitigation Measures During the Acceleration Phase of the COVID-19 Pandemic. Academic Emergency Medicine. 2020.

31. Law T. 'We Carry That Burden.' Medical Workers Fighting COVID-19 Are Facing a Mental Health Crisis. Time. 2020 April 10, 2020. https://time. com/5817435/covid-19-mental-health-coronavirus/ Accessed 4 Aug 2020

32. Pfefferbaum B, North CS. Mental Health and the Covid-19 Pandemic. N Engl J Med. 2020;383(6):510-2.

33. Beletsky L, Wakeman SE, Fiscella K. Practicing What We Preach — ending physician health program bans on opioid-agonist therapy. N Engl J Med. 2019;381(9):796-8.

34. Tsai AC, Kiang MV, Barnett ML, Beletsky L, Keyes KM, McGinty EE, et al. Stigma as a fundamental hindrance to the United States opioid overdose crisis response. PLoS Med. 2019;16(11):e1002969.

35. Henderson C, Evans-Lacko S, Thornicroft G. Mental illness stigma, help seeking, and public health programs. Am J Public Health. 2013;103(5):777-80.

36. Bansal P, Bingemann TA, Greenhawt M, Mosnaim G, Nanda A, Oppenheimer J, et al. Clinician wellness during the COVID-19 pandemic: extraordinary times and unusual challenges for the allergist/immunologist. J Allergy Clin Immunol. 2020;8(6):1781-90.

37. Pereira-Lima K, Mata DA, Loureiro SR, Crippa JA, Bolsoni LM, Sen S. Association between physician depressive symptoms and medical errors: a systematic review and meta-analysis. JAMA Network Open. 2019;2(11):e1916097.

38. Himmelstein KEW, Venkataramani AS. Economic Vulnerability Among US female health care workers: potential impact of a \$15-per-hour minimum wage. Am J Public Health. 2018;109(2):198-205.

39. Renwick D, Dubnow S. Exclusive: Over 900 Health Workers Have Died of COVID1-9. And the Toll is Rising. In: Network KH, editor. 2020. https:// khn.org/news/exclusive-over-900-health-workers-have-died-of-covid -19-and-the-toll-is-rising/ Accessed 4 Aug 2020

\section{Publisher's Note}

Springer Nature remains neutral with regard to jurisdictional claims in published maps and institutional affiliations. 